\title{
ESTABELECENDO O DEBATE NA ÉTICA CONTEMPORÂNEA
}

Osvaldo Guariglia*

SÍNTESE - Neste artigo, o autor apresenta um balanço do debate ético contemporâneo, partindo da oposição central entre posições universalistas e visões particularistas.
ABSTRACT - In this paper, the author offers a survey of the contemporary debate in Ethics which focuses on the dispute between universalist and particularist views.

PALAVRAS-CHAVE - Ética. Universalismo. KEY WORDS - Ethics. Universalism. Particularism. Particularismo.

Sem dúvida, a última década foi um dos períodos mais frutíferos na história do pensamento ocidental contemporâneo no tocante à ética, em especial, no que diz respeito à ética pública e à filosofia política. Neste período, foram publicadas obras fundamentais como Sources of the Self, de Charles Taylor, Political Liberalism, de John Rawls e Faktizität und Geltung, de Jürgen Habermas, que resultaram numa controvérsia que ultrapassa os limites do mundo anglo-saxão. A comunidade de língua espanhola é, talvez, uma das que mais parece interessada pelos problemas macroéticos, tal como o mostram obras importantes como a de Carlos Nino, Etica y derechos humanos, de Javier Muguerza, Desde la perplejidad, e de Ernesto Garzón Valdés, Derecho, ética y politica. Não é, de forma alguma possível, resenhar e discutir os temas centrais de todos estes livros complexos, mas não seria irrazoável expor meu balanço pessoal sobre a discussão, em especial, com uma visão que sintetize aqueles problemas que permanecem abertos.

Devo reconhecer que considero central a oposição entre as visões universalistas e particularistas da ética, em torno da qual se subordinam os problemas principais da disciplina. Esta oposição central tem versões diferentes; a mais conhecida é, sem dúvida, a que se dá entre liberais e comunitaristas. Sem dúvida, esta não é a única controvérsia, já que existe na América Latina uma competência entre os defensores da ética universalista, como Nino e eu, por exemplo, e os representantes da ética latino-americana, a denominada filosofia da libertação.

* Professor da Universidade de Buenos Aires. 
Não pretendo fazer um resumo de todas estas oposições, mas sim propor três grandes contradições em três diferentes níveis, a partir dos quais surgem os desacordos mais básicos entre ambas tendências.

A primeira delas tem lugar no nível metodológico: refiro-me à distinção tradicional entre o correto e o bom. Como é sabido, a orientação ao correto define a ética deontológica, isto é, uma ética que tem, entre suas propriedades, um método procedimental de decidir a correção das ações morais por meio de sua subsunção sob um princípio, ou uma classe de princípios, universalmente válidos. Por conseguinte, os limites deste tipo de ética são muito amplos, e, conseqüentemente, se restringem aos limites das relações interpessoais para regulá-las e proibir vários tipos de coerção. Por outro lado, a ética de bom tende a sustentar a existência de um ou alguns fins positivos para as vidas dos indivíduos, e, ao mesmo tempo, da sociedade, fins que mobilizam as paixões, interesses e inteligência dos membros de um grupo, na prossecução desses fins. À diferença da anterior, este tipo de ética está necessariamente entrelaçada com o tecido social de uma sociedade dada e tem uma resposta, não somente para os conflitos de interesses entre seus membros, mas também para sua necessidade de guia nas escolhas de suas vidas.

A questão acerca destas duas diferentes concepções da ética, isto é, a grande questão metodológica de nossa tarefa como filósofos morais, se refere à unidade ou diversidade de nossa investigação. Em outras palavras, seu objeto é o mesmo, visto desde duas perspectivas diferentes, ou se trata melhor de dois diferentes objetos de duas disciplinas diferentes, que casualmente tem o mesmo nome, a saber, ética? Deixo esta pergunta aberta, mas gostaria de fazer uma observação referida ao trabalho metodológico que nós, enquanto filósofos, fazemos no caso de um ou outro tipo de ética: aquela que teoriza sobre o correto, tratar de construir ou reconstruir as regras subjacentes sob as quais todos discorremos em nossos argumentos morais, para que o conteúdo normativo destas regras salta à luz. Por outro lado, a tarefa daqueles que especulam sobre o bom é antes como a atividade do antropólogo que descreve os costumes de outras pessoas, com uma diferença importante: seu objetivo não é meramente informar sobre a conduta real dos aborígenes observados, mas também alentar a outros para que os imitem. É este último traço, sobretudo, o que dá ao teorizador sobre o bom, uma ambigüidade inevitável.

A segunda grande oposição se refere à idéia central da identidade do sujeito moderno: por um lado, a autonomia como um ideal que unifica a autodeterminação, responsabilidade e liberdade; por outro, a autenticidade, isto é, uma forma de vida peculiar que prioriza a lealdade a uma escolha particular, seja individual ou coletiva, por ser a escolha de um mesmo. Esta oposição, naturalmente, tem diferentes formas, e traz consigo um amplo espectro de diversas conseqüências. A autonomia está associada com uma ética universalista que garante a todos, por meio de seus princípios e procedimentos, uma igual oportunidade de desenvolver suas capacidades, a fim de selecionar e reforçar sua própria concepção da vida boa. De modo que o eu da autonomia se concebe como um eu impessoal, não involucrado ou livre de travas, que só pensa consigo mesmo acerca de seus deve- 
res e direitos. Trata-se, obviamente, de uma abstração, que deve preencher-se com o material real da vida diária, mas é verdade, sem dúvida, que uma visão universalista da vida moral se restringe a estabelecer os fundamentos e pilares do eu moderno, deixando o resto do edifício em mãos de seu dono, que é livre para completá-lo como prefira. Em outras palavras, os caminhos pelos quais cada um de nós, enquanto sujeitos modernos, encontramos a própria realização na sociedade moderna é uma questão de livre escolha individual. Uma ética universalista não tem nada que dizer sobre isto, sempre que respeitemos e contribuamos a fim de que outros, por sua vez, também respeitem o esquema básico de igualdade de direitos e oportunidades para todos, ou sempre que vivamos e contribuamos para viver em democracia.

A autenticidade, ao contrário, é uma noção um tanto escorregadia, que tem muitos aspectos e diferentes significados de acordo com os traços peculiares que tem cada forma de vida. Originada no individualismo moderno, evoluiu de tal modo que inclui todas aquelas características que definem certas pessoas segundo suas marcas básicas de identidade, como linguagem, religião, gênero, orientação sexual etc. Em termos de um conhecido teórico, Charles Taylor, "brevemente, podemos dizer que a autenticidade (A) involucra (i) criação e construção, assim como descobrimento, (ii) originalidade, e, freqüentemente, (iii) oposição às regras da sociedade, e, inclusive potencialmente, ao que reconhecemos como moral. Mas também é certo" [...] que ela (B) requer (i) abertura a horizontes de significado [...] e (ii) uma autodefinição no diálogo. Deve-se admitir que estas postulações estejam eventualmente, em tensão" (Taylor, 1991, p. 66). Como Taylor mesmo admite, a tensão se torna inevitável devido ao reconhecimento da diferença por parte dos outros membros da sociedade como parte de um ideal de auto-realização, como a autenticidade. Mas este reconhecimento pode chocar-se com idéias diferentes do bom, que existem em qualquer sociedade multicultural, como são quase todas as sociedades contemporâneas. De modo que a tensão se converte realmente em uma contradição entre as mesmas condições sob as quais um ideal de autenticidade pode crescer e desenvolver-se e a conseqüência de seus traços mais extremos.

Pergunto-me se ambos ideais, autonomia e autenticidade, estão no mesmo nível; minha resposta pessoal é que não estão, mas deixo esta segunda pergunta aberta e passo à terceira oposição principal, entre uma concepção da cidadania liberal e uma republicana.

O liberalismo enfatiza o gozo daqueles direitos que permitem aos cidadãos escolher e perseguir concepções permissiveis da vida boa. Ao fazê-lo, os cidadãos reclamam ao Estado que, por sua vez, deve ser reconhecido como legítimo dentro de uma sociedade justa e democrática. Isto dá lugar à seguinte idéia: há uma lista dos mesmos bens primários que é necessária para as concepções do bem dos cidadãos, independentemente de quão distintos sejam seu conteúdo e as doutrinas religiosas e filosóficas relacionadas. Estes bens primários incluem "os mesmos direitos, liberdades e oportunidades básicas e os mesmos meios para todo fim como ingresso e riqueza, estando todos apoiados pelas mesmas bases sociais do 
auto-respeito. Estes bens [...] são coisas que os cidadãos necessitam enquanto pessoas iguais e toda pretensão no que diz respeito a estes bens é apropriada" (Rawls, 1993, p. 180).

Contra esta imagem do cidadão de uma sociedade democrática, levantaramse algumas objeções à sua concepção de cidadão como pessoa privada. A concepção neoclássica tradicional do cidadão havia enfatizado, em contraposição, as virtudes participativas dentro do domínio comum do Estado. $\mathrm{O}$ ideal de "governar e ser governado" (Aristóteles) é, para esta concepção, parte essencial de uma vida digna, e uma sociedade organizada em torno deste ideal "partilharia e apoiaria, a sociedade, ao menos essa noção da vida boa" (Taylor, 1995, p. 199). De modo que esta nova versão de "republicanismo", especialmente o norte-americano, restabelece a concepção tradicional do cidadão clássico como intervindo ativamente no governo da cidade, indo às assembléias e concebendo a "libertade" como liberdade política para tomar e usar o poder (cf. Walzer, 1994, p. 55)

À primera vista, temos novamente aqui a oposição de Benjamin Constant entre as "liberdades dos modernos" e as "liberdades dos antigos", isto é, uma contradição que pensadores políticos clássicos como Rousseau e Kant pretenderam superar e que estava profundamente arraigada, desde o começo, nas estruturas das sociedades modernas. Tal como assinalei no tocante à primeira oposição entre a ética do correto e a ética do bom, aqui novamente nos encontramos com duas formas possiveis para considerar este tema complexo: ou há duas concepções diferentes e possivelmente complementárias de uma e a mesma realidade social e política, ou há efetivamente duas realidades completamente diferentes e incomensuráveis nas quais o eu moderno se encontra cronicamente cindido. Propuseramse soluções a este problema a partir de ambas direções, mas estão longe de ser satisfatórias.

Gostaria agora de voltar às perguntas abertas que deixei sem responder, e farei alguns comentários sobre os pontos em jogo. No nível metodológico, destaquei que a questão sobre as duas diferentes concepções da ética, isto é, a ética do correto e a ética do bom, se refere à unidade ou diversidade de nossa investigação. Em outras palavras: é o objeto da ética uno, observado desde duas perspectivas diferentes, ou há dois objetos diferentes para duas disciplinas distintas, que só casualmente têm o mesmo nome, a saber, a ética? Alguns filósofos comunitários, como Michael Walzer, parecem crer na possibilidade de duas concepções da ética, de algum modo convergentes, uma, densa e maximalista e outra, tênue e minimalista, que se superpõem em alguns pontos cruciais ou em certos momentos dramáticos, como durante a queda do regime comunista na Europa oriental. Mas as concepções convergentes deste tipo se refeririam somente aos juizos e não às razões que causam aqueles momentos, porque têm suas raízes na narrativa da própria história e são, portanto, intraduzíveis (cf. Walzer, 1994, p. 1-19). Realmente duvido que tal operação seja possível. Admiro a narrativa potente e, em muitos aspectos, iluminadora de Walzer e Taylor, mas não encontro nenhuma conexão fácil entre os temas envolvidos por ela e o sóbrio sistema de princípios e direitos que tratamos de reconstruir uma ética universalista. Um sistema assim não tem 
necessidade de explicações, mas só de um enunciado coerente e claro, como a Declaração dos Direitos Humanos das Nações Unidas. Para muitas culturas foi impossivel criar um sistema de direitos que protejam a liberdade, a integridade e 0 conjunto de liberdades que a Declaração garante na própria vida moral; para outros, como os países latino-americanos que tiveram desde meados do século XIX sistemas de direitos e princípios similares em suas constituições, o retorno à validez ilimitada dos direitos humanos foi uma revolução democrática depois de meio século de regimes demagógicos e ditaduras militares. Esta revolução democrática foi imposta pela opinião pública mundial e não pela autocrítica da sociedade civil. Em resumo, o bem se diz de muitas maneiras, como dissera Aristóteles vários séculos antes, e não é fácil ver como os significados particulares do bem assumidos em cada sociedade podem fundir-se numa concepção compreensiva mas neutra, que abarque toda sua ampla gama de diferentes significados.

A segunda pergunta que deixei em aberto é a seguinte: os ideais de autonomia e autenticidade estão no mesmo nível ou não? Como mostrei antes, minha resposta pessoal seria que não, e gostaria de explicar por que penso assim. A autonomia não é nem deve ser uma propriedade de fato, mas requer somente ser um postulado da pessoa moral que deve ser assegurado por um conjunto de princípios e/ou normas universais. Não é necessária a presença em ato da autonomia em um ser humano para exigir respeito a ele, como nos casos de crianças pequenas ou pessoas gravemente enfermas que não podem expressar claramente sua vontade. Por outro lado, a autenticidade não existe se não for uma conquista efetiva de um indivíduo ou de um grupo de seres humanos que decidiram viver suas vidas segundo algum estilo ou ideal auto-imposto. A autenticidade pressupõe estar de posse de autonomia enquanto um traço claro do sistema de princípios e direitos reconhecidos por uma sociedade determinada, mas a inversa não é verdadeira. A assimetria é uma prova clara de que não estão no mesmo nivel. Em troca, a autenticidade é uma certa maneira de gozar dos recursos normativos dados para a realização de nossa autonomia e, talvez, não a mais elevada. Talvez sejam ideais melhores o indivíduo perfeitamente prudente da tradição aristotélica e estóica ou o homem de sabedoria prática da tradição kantiana.

O último problema que coloquei com respeito às duas distintas visões do cidadão - a que o concebe como uma pessoa privada que goza das vantagens garantidas pelos direitos civis, e a outra, que o concebe como um membro ativo do governo, indo às assembléias e entendendo a liberdade como liberdade política para tomar e usar o poder - é muito difícil de captar e ainda mais difícil de resolver. Gostaria de discuti-lo detidamente.

Considerarei primeiro uma versão extrema de republicanismo que alguns especialistas, como Jonathan Barnes, encontram numa passagem da Política VIII 1, 1337 a 26-32, de Aristóteles, deixando de lado a questão de se é uma interpretação justa do texto aristotélico, a saber: "O comportamento no que é comum deve ser também comum. Ao mesmo tempo, também não se deve pensar que nenhum cidadão se pertence a si mesmo, mas que todos pertencem à cidade, posto que cada um é uma parte dela, e o cuidado da parte deve naturalmente orientar-se 
pelo cuidado do todo" (trad. cast. de J. Marías y M. Araujo, Instituto de Estudos Políticos, Madrid, 1951, p. 149). Uma interpretação estrita do significado desta passagem seria a seguinte, de acordo com Barnes: "Se os F são partes de G, então os F só podem definir-se em função dos G; portanto, os F são dos G simpliciter no sentido de que ser um cidadão é estar em uma certa relação com respeito a um Estado [...] Mas os seres humanos são essencialmente animais políticos, isto é, são essencialmente cidadãos. Os cidadãos dependem logicamente dos Estados. Portanto, os seres humanos são logicamente dependentes dos Estados. Ser um humano é, inter alia, ser de um Estado. Portanto [...] o cuidado do homem deve ser o bem do Estado" (Barnes, 1990, p. 263). Não sem razão, Barnes fala de "totalitarismo" com respeito a esta concepção e creio que estaríamos de acordo com ele. Em outras palavras, esta concepção da relação entre os cidadãos e o Estado representa uma concepção extrema e compreensiva da vida política, enquanto a única boa vida possível e, como tal, incompatível com qualquer concepção moderna do cidadão como sendo ademais uma pessoa privada. Mais ainda, diversos tipos de fundamentalismos, incluindo o leninismo e o fascismo, podem ser considerados como versões atuais deste pensamento político antigo.

Mas há outra concepção de "republicanismo clássico", com o qual um ponto de vista universalista liberal não tem nenhuma oposição fundamental. Tal concepção apoiaria a opinião de que "se os cidadãos de uma sociedade democrática devem preservar seus direitos e liberdades básicas, incluindo as liberdades civis que asseguram a liberdade da vida privada, eles também devem ter até certo ponto as "virtudes políticas", e estar dispostos a formar parte da vida pública. [...] A segurança das liberdades democráticas requer a ativa participação de cidadãos que possuam as virtudes políticas necessárias para manter um regime constitucional" (Rawls, 1993, p. 205). Até aqui, não há problema. Sem dúvida, a pergunta seria: como é possível? Não é de modo algum evidente quais razões moveriam os cidadãos, que se encontram confortavelmente instalados nas instituições da democracia, a se ocuparem com os problemas da vida pública. Recentemente Habermas colocou o dedo nesta ferida, ao observar que "desde a perspectiva da teoria da justiça, o ato de fundar uma constituição democrática não pode repetirse sob as condições institucionais de uma sociedade justa já constituída, e o processo de realizar o sistema de direitos básicos não pode assegurar-se como um processo contínuo. Não é possível aos cidadãos sentir este processo como aberto e incompleto, como o exigem, não obstante, as mutantes circunstâncias históricas" (Habermas, 1995, p. 128).

Creio que parte da solução que podemos encontrar consiste em repensar a relação entre a esfera privada e a pública da cidadania moderna. Não há dúvida de que há, como destacou Habermas, "uma relação dialética" entre autonomia privada e pública, porque a lei pública que possibilita a existência de instituições políticas se dirige a pessoas "que não poderiam nem sequer receber o status de sujeitos legais sem direitos privados subjetivos", de modo que a "autonomia privada e pública dos cidadãos se pressupõem mutuamente" (Habermas, 1995, p. 130). Mas não é tão fácil ver de que modo ambas esferas se encontram procedimentalmente 
correlacionadas, e até que ponto este procedimento requer uma severa limitação dos problemas e temas propostos para a discussão pública, tal como mostrou recentemente McCarthy (cf. McCarthy, 1994, pp. 44-63). É impossível seguir adiante com este tema aqui. Só gostaria de fazer a seguinte observação: a larga experiência das agitadas democracias dos países do sul da América do Sul ensinou a seus cidadãos que a luta pela vigência dos direitos humanos nunca é só um instrumento para a defesa de seus próprios direitos civis, mas que é também, ao mesmo tempo, um objetivo político, que por si mesmo muda as estruturas sociais e políticas da sociedade. Neste sentido, pode ser que o liberalismo universalista e o republicanismo clássico sejam só duas formas distintas de olhar a mesma realidade. Já que consideramos esta realidade como um sistema institucionalizado de direitos e deveres, baseado em princípios de justiça universais, adotamos a perspectiva do cidadão individual; se, em troca, a consideramos como um modelo imperfeito de democracia que temos que melhorar e manter vivo, então adotamos a perspectiva do cidadão ativo que concebe a continuidade e melhoria da democracia enquanto tal como um bem geral. No primeiro caso, concebemos o estado de coisas desde a perspectiva da razão normativa; no segundo, desde a perspectiva da prudência, precisamente como a faculdade do razoável, que media entre as restrições da situação e as normas, por um lado, e os fins mais amplos que podemos desejar para nós e inspirar a outros para que os escolham e persigam, por outro lado. Ambos são usos da mesma faculdade, a saber, a razão prática no sentido amplo, que, enquanto tal, pode servir de ponte entre as duas autonomias do cidadão moderno mencionadas anteriormente.

Para concluir, gostaria de enfatizar o que disse no começo: considero a oposição entre as concepções das éticas universalistas e particularistas como a discussão central, em torno da qual se ordenam os problemas centrais da disciplina. Apesar das diferenças nacionais e culturais, as três grandes oposições de que tratei aqui estão presentes em toda discussão sobre ética ali onde podemos encontrar uma tradição filosófica separada do pensamento religioso, metafísico ou ideológico. Isto me parece ao menos um claro sinal do universalismo dos problemas que enfrentamos, por mais divergentes que sejam as respostas a eles.

\section{Referências bibliográficas}

BARNES, J. Aristotle and political liberty. In: PATZIG, G. (ed.). Aristoteles' "Politik". Göttingen: Vandenhoeck \& Ruprecht, 1990.

GARZÓN VALDÉS, E. Derecho, ética y politica. Madrid: Centro de Estudios Constitucionales, 1993.

GUARIGLIA, O. Moralidad: ética universalista y sujeto moral, Buenos Aires-México: FCE, 1996.

HABERMAS, J. Faktizität und Geltung. Francfurt: Suhrkamp, 1992.

- Reconciliation through the public use of reason: remarks on John Rawls's political liberalism. Journal of Philosophy, 92, Mar. 1995, p. 109-131.

MCCARTHY, Th. Kantian constructivism and reconstructivism: Rawls and Habermas in dialogue. Ethics, 105, Oct. 1994, p. 44-63.

MUGUERZA, J. La alternativa del disenso (en torno a la fundamentación ética de los derechos humanos). In: PECES BARBA, G. (ed.). El fundamento de los derechos humanos. Madrid: Debate, 1989, p. 19-56.

— Desde la perplejidad. México-Madrid-Buenos Aires: FCE, 1990. 
NINO, C. Ética y derechos humanos. 2. ed. Buenos Aires: Astrea, 1989.

RAWLS, J. Political liberalism. New York: Columbia University Press, 1993.

. Reply to Habermas. Journal of Philosophy, 92, Mar. 1995, p. 132-180.

TAYLOR, Ch. Sources of the self: the making of modern identity. Cambridge, Mass.: Harvard University Press, 1989.

The ethics of authenticity. Cambridge, Mass.: Harvard University Press, 1991.

. Philosophical arguments. Cambridge, Mass.: Harvard University Press, 1995.

WALZER, M. Spheres of justice. 2. ed. Oxford: Blackwell, 1985.

. The communitarian critique of liberalism. Political Theory, 18, 1990, p. 6-23.

. Thick and thin: moral argument at home and abroad. Notre Dame-London: University of Notre Dame Press, 1994. 